\title{
A Tradução como ferramenta pedagógica no Ensino de Línguas
}

\author{
LAVIOSA, Sara. Translation and Language Education: Pedagogic Approaches \\ explored. New York: Routledge, 2014, p.187.
}

Alane Melo da Silva ${ }^{1}$

Desde o estabelecimento dos Estudos da tradução tem sido um tema recorrente de discussão a relação entre tradução e o ensino de Línguas Estrangeiras. Nesse livro, Sara Laviosa, professora de Língua Inglesa e tradução na Itália, tem como objetivo Propor um diálogo entre professores de línguas e tradutores sobre o papel da tradução no desenvolvimento de competências comunicativas, metalinguísticas e transculturais, que são de fundamental importância na formação de profissionais da área no século XXI.

Nas últimas duas décadas tem havido um crescente interesse em definir o atual lugar e função da tradução no ensino de línguas estrangeiras. A recente preocupação com a tradução como uma ferramenta de aprendizagem, e habilidade profissional, vem originando novas pesquisas na área do ensino de Línguas e Estudos da Tradução. Assim, esse livro destina-se a professores de idiomas, tradutores e alunos em programas de graduação de línguas modernas, bem como pesquisadores em ensino de segunda língua e pedagogia de tradução interessados nessa temática.

O primeiro capítulo fornece um breve histórico do lugar e função da tradução na educação em $L E$, relembrando a importância do Método Gramática-Tradução e, relatando as mudanças ocorridas com o advento do Método Comunicativo. Desde o século XVIII,o método Gramática-tradução era considerado o mais importante no ensino de LE. $O$ método gramática-tradução foi a primeira e mais antiga metodologia para ensino de línguas tendo inicio nas línguas clássicas.

O objetivo deste método era permitir o acesso a textos literários e a um domínio da gramática normativa privilegiando aspectos linguísticos em detrimento dos aspectos comunicativos. A tradução era à base de compreensão da língua em estudo, como materiais didáticos o professor utilizava o dicionário e o livro de gramática na sala de aula. A aprendizagem para esse método era feita através da memorização de regras e compreensão de estruturas gramaticais. Porém, a partir de meados do século XX com o surgimento de novas

\footnotetext{
${ }^{1}$ Mestranda no Programa de Pós-Graduação em Estudos da Tradução - POET, da Universidade Federal do Ceará. E-mail: alanepoet@gmail.com
} 
metodologias e pesquisas na área do ensino de línguas, a tradução passou a ser amplamente excluída como parte do aprendizado de uma língua estrangeira.

No entanto, a autora relembra nesse primeiro capítulo que inúmeras pesquisas realizadas confirmam que a tradução é uma ferramenta de ensino que tem provado ser benéfica do nível mais básico até o mais avançado das competências linguísticas. A admissão ou exclusão da tradução como exercício de aprendizagem depende de como o processo é concebido; isto, por sua vez, é influenciado por como o propósito é definido em uma dada metodologia.

O capítulo dois traça o desenvolvimento das principais teorias em favor do uso de várias formas de tradução na educação de línguas estrangeiras. Laviosa afirma que aprender a traduzir uma ampla gama de tipos de texto, registros e estilos, tanto na linguagem escrita quanto na falada, aumenta uma variedade de habilidades que são essenciais na aquisição de segunda língua e no ambiente de trabalho.

Portanto, a tradução é um exercício útil para entender as diferenças e semelhanças entre culturas e melhorar o conhecimento de ambas as línguas. Cook, um importante estudioso sobre o tema, expõe algumas razões da necessidade da tradução no ensino de LE. Ele afirma que na sociedade atual, cada vez mais multilingue e multicultural, a tradução é uma habilidade muito necessária por muitas razões: pessoal (por exemplo, casamentos mistos), educacional (por exemplo, passar em uma prova) social (por exemplo, comunidades de imigrantes) e profissional (por exemplo, comunicação internacional), (COOK, 2010 P.109)

Do ponto de vista reformista social, a tradução pode promover valores liberais, humanistas e democráticos, porque facilita a linguagem e encontros culturais, juntamente com uma compreensão e consciência da diferença. Além disso, por manter a presença do L1 no processo de aprendizagem de línguas estrangeiras, a tradução pode ajudar a "preservar as identidades dos falantes de línguas ameaçadas e promover a conscientização entre falantes de línguas poderosas da natureza e situação dos outros". (De uma perspectiva educacional humanista, Cook afirma que a tradução como uma forma de instrução bilíngue é vista favoravelmente pelos estudantes. Finalmente, do ponto de vista acadêmico, "a instrução em tradução provavelmente envolve um elemento acadêmico, na medida em que envolve necessariamente conhecimento declarativo explícito sobre linguagem e línguas, e uma metalinguagem para sua descrição formal" (COOK, 2010 p. 121).

Laviosa ressalta que a tradução é uma forma de desenvolver habilidades metalinguísticas, pois estimula a discussão sobre uma variedade de problemas como erros de tradução, avaliação crítica de legendas de filmes, dilemas de tradução (por exemplo, o uso de linguagem sexista ou racista no texto fonte) e expressões não traduzíveis como trocadilhos ou jogos de palavras. Além de seus usos tradicionais no aprimoramento do conhecimento declarativo das duas línguas, a tradução pode ser usada como uma tarefa comunicativa, com foco no significado, que simula situações da vida real.

O terceiro capítulo examina as interpretações de relação entre língua e cultura que formam a pedagogia multilíngue elaborada por Claire Kramsch no ensino de línguas estrangeiras e a abordagem holística para traduzir a cultura proposta por Maria Tymoczko para os estudos de tradução. A linguagem é um ecossistema semiótico que coopera com outros processos de construção de significado, é sempre uma atividade de construção de significado que ocorre em uma complexa rede de sistemas complexos que se entrelaçam entre si, bem como com todos os aspectos dos mundos físico, social e simbólico. Dessa forma, uma perspectiva ecológica é relacional, na medida em que visa desvelar as conexões que professores e alunos mantêm com o seu ambiente, e reflexiva uma vez que examina as suposições tradicionais, como a dicotomia entre o conhecimento cotidiano dos professores e alunos sobre a linguagem e a necessária para o trabalho acadêmico (VAN LIER 2002, p.144). 
O objetivo dessa pedagogia é promover uma compreensão da linguagem como um sistema que reflete, constrói e transforma a cultura. Isto é crucialmente importante para a formação do indivíduo multilíngue que precisa desenvolver competência translingual e transcultural, que valoriza a capacidade de operar entre as línguas e implica a capacidade de refletir sobre o mundo e sobre nós mesmos através das lentes de outra língua e cultura. (TYMOCZKO 2007, p.3). Desenvolver o pensamento crítico sobre a interdependência da linguagem e da cultura está no cerne de pedagogias orientadas ecologicamente, como as propostas por Claire Kramsch e Maria Tymoczko.

O quarto capítulo apresenta as perspectivas ecológicas sobre aquisição de segunda língua. Essa visão afirma que "a aprendizagem é uma atividade humana relacional e não-linear, co-construída entre os seres humanos e seu ambiente, dependente de sua posição no espaço e da história, e um local de luta pelo controle do poder social e da memória cultural" (KRAMSCH 2002 p. 5).

Diante dessa premissa, uma pedagogia da linguagem ecológica visa fomentar uma compreensão crítica dos múltiplos mundos do discurso que coexistem em qualquer sala de aula de línguas e decorrem da interação entre professor e alunos e entre alunos como membros de uma comunidade.

Laviosa defende a proposta de Kramsch, como algo de vital importância para explorar mais detalhadamente a natureza da tradução e sobre a estrutura ecológica que ela propõe. O quinto capítulo explora a abordagem holística para tradução de diferenças culturais elaborada por Maria Tymoczko (2007). A autora defende que a disciplina dos estudos de tradução se move em direção a uma compreensão multilingue, intertemporal e transcultural das práticas e produtos da tradução em todo o mundo. Ela argumenta que a noção de tradução como o processo de transferência de um texto de uma língua de origem para uma língua de destino e o produto, ou texto de destino, resultante desse processo não pode ser adotado como base para uma disciplina global de estudos de tradução e apresenta os conceitos de representação, transmissão e transculturalidade que segundo sua visão estão de acordo com os avanços globais e pós modernidade.

Assim, sobre a relação entre o tradutor e essa perspectiva tradutória Tymoczko assinala: "A cultura é o domínio onde as diferenças humanas são mais manifestas" e as representações dessas diferenças são "secundárias em importância apenas para a performance e prática de formas culturais de formação de identidade e solidariedade de grupo", bem como para reivindicações relativas à consideração e reconhecimento em interações culturais"(TYMOCZO,2007 p. 221).

Por isso, traduzir cultura envolve representar, transmitir e transculturar não apenas elementos culturais materiais, mas também signos, símbolos, códigos, crenças, valores, ideias, ideais e ideologias (Tymoczko, 2007 p. 26). Segue-se que os tradutores que realizam a tradução cultural exercem uma tradução na perspectiva ética, ideológica e política. Assim, a abordagem de Tymoczko oferece uma noção de tradução que complementa a visão de Kramsch da tradução como um repensar de um contexto em termos de outro e como um processo que revela as diferenças culturais na relação entre linguagem e pensamento.

O sexto capítulo examina os fundamentos convergentes da competência simbólica e da tradução cultural holística e postula que esses dois princípios estão interconectados tanto na teoria como na prática. A competência simbólica e a tradução cultural holística estão enquadradas numa ampla perspectiva ecológica que teoriza a linguagem como um sistema simbólico que constrói a própria realidade a que se refere e que atua sobre essa realidade através das categorias que impõe a ela afetando assim a relação entre os falantes e a realidade como eles a percebem. "(KRAMSCH 2009, p.5).

De fato, todos os seres humanos podem ser considerados tradutores latentes, pois são capazes de aprender novas palavras, conceitos, padrões culturais de outras línguas. (Tymoczko 2007: 231). Ao adquirir uma língua 
estrangeira, eles podem descobrir "significados inesperados, verdades alternativas que ampliam o alcance do dizer e do imaginável" (KRAMSCH, 2009, p. 15).

Assim, os indivíduos multilíngues e tradutores precisam ser criadores de significado interculturalmente competentes, auto-reflexivos e responsáveis. Como Kramsch sustenta, os aprendizes de línguas precisam adquirir "uma mentalidade simbólica que conceda tanta importância à subjetividade e à historicidade da experiência quanto às convenções sociais e as expectativas culturais de qualquer comunidade estável de falantes" (KRAMSCH, 2010, P.12). O sétimo capítulo reafirma a viabilidade de se adotar uma pedagogia holística da linguagem e da tradução com alunos em diferentes níveis de aprendizagem, pois mostra como a interação entre teoria, pesquisa e prática na sala de aula fomenta a auto-reflexão e o pensamento crítico, ao mesmo tempo em que motiva os alunos a aprenderem as línguas dentro de uma ampla perspectiva intercultural e interdisciplinar. Como Laviosa afirma: " A linguagem é um sistema semiótico que coopera com outros processos de construção de significado, é sempre uma atividade de construção de significado que ocorre em uma complexa rede de sistemas que se entrelaçam entre si, bem como com todos os aspectos dos mundos físico, social e simbólico."

O oitavo capítulo afirma a importância de repensarmos a tradução de acordo com uma perspectiva holística. Pois a tradução trouxe à luz muitas diferenças e semelhanças interessantes e sutis na construção do significado, além daquelas evidenciadas durante a exploração da mensagem multimodal. Ao experimentar as limitações da língua-alvo e a necessidade de aprofundar as nuances do significado de um texto, contexto e intertextos para transmiti-los na língua materna, os alunos se conscientizaram da possibilidade real de expressar suas próprias vozes através da tradução cultural.

Há milênios, a atividade de tradução está presente na história da humanidade. Seja na literatura ou no direito, o ato de traduzir é essencialmente uma atividade complexa que vem sendo realizada pelo ser humano, e não deve ser compreendida apenas como transferência semântica de uma língua para outra, mas, antes de tudo, considera-se a compreensão daquilo que se lê e a produção de um novo sigificado a partir de um texto.

Concordamos com WITTE (2009) que afirma: "a tradução no ensino de línguas não tem, de forma alguma, o objetivo de educar tradutores; ao contrário, é uma atividade que pode estimular o potencial cognitivo de um aprendiz adulto ou adolescente e, portanto, deve complementar outras atividades, e não substituí-las." (WITTE, 2009, p.2).

Desde o Método da Gramática-Tradução, até os dias atuais, a tradução tem desempenhado um relevante papel no aprendizado e ensino de línguas estrangeiras e assim acreditamos que ainda tem total relevância em sala de aula quando usada como uma ferramenta de aprendizagem que proporcione motivação, aprendizado e aquisição de competências culturais relevantes para alunos do século XXI. 